\title{
Análise microestrutural de um aço AISI 4350 submetido a tratamentos térmicos para a formação de bainita
}

\author{
Microstructural analysis of an AISI 4350 steel subjected to heat treatments \\ for the formation of bainite
}

Rosiane Castro Nogueira ${ }^{1}$, Antônio Jorge Abdalla², Tomaz Manabu Hashimoto', Marcelo dos Santos Pereira ${ }^{1}$

\section{RESUMO}

O aço ultra-resistente AISI 4350, destinado a aplicações aeronáuticas, com médio teor de carbono e baixa liga, possui uma microestrutura complexa composta por diversas fases, tais como: bainita, ferrita, austenita retida e martensita. Diferentes microestruturas multifásicas podem ser formadas neste aço, com predomínio de uma destas fases, em função dos tratamentos térmicos selecionados e aplicados. Neste trabalho foi formada uma microestrutura com predomínio de bainita. Sua análise microestrutural foi realizada por microscopia óptica e para possibilitar a quantificação das fases foi utilizada a técnica de tríplice ataque. No tríplice ataque os reagentes utilizados foram: Nital 2\%, que destaca as microestruturas ferrita e austenita (fases claras) das demais fases (escuras); solução aquosa de metabissulfito de sódio 10\%, que identifica a austenita (fase clara) separando-a das outras fases (escuras); LePera, para realçar o constituinte M.A. (martensita e austenita retida) que apresenta um aspecto branco brilhante(1,2). Por sua vez, sabese que a microestrutura do aço tem significativa influência nas propriedades mecânicas, e este é dependente dos tratamentos térmicos aplicados. Este trabalho tem por finalidade encontrar um tempo ótimo para a obtenção de uma estrutura ferrítica-bainítica. Observou-se que a transformação bainítica a $280^{\circ} \mathrm{C}$ é mais efetiva para tempos superiores a 300 s e que com 1.800 s de tratamento praticamente toda a matriz tornou-se bainítica.

Palavras-chave: Tratamentos térmicos, Aço AISI 4350,

Microestrutura bainítica.

\begin{abstract}
The ultrahigh strength AISI 4350 steel, intended for aviation applications, with medium-carbon low alloy content, has a complex microstructure consisting of various phases, such as: bainite, ferrite, retained austenite and martensite. Different multiphase microstructures can be formed in this steel, with a predominance of one of these phases, in function of the heat treatments selected and applied. This work formed a microstructure with predominance of bainite. Microstructural analysis was performed by optical microscopy and to allow quantification of the phases was used the triple chemical etching technique. In the triple chemical etching reagents used were: $2 \%$ Nital, which highlights the microstructures ferrite and austenite (clear phases) of the other phases (dark); aqueous solution of $10 \%$ sodium metabisulfite, which identifies the austenite (stage clear) separating it from other phases (dark); LePera, to highlight the constituent M.A. (martensite and retained austenite) which features a bright white appearance ${ }^{(1,2)}$. In turn, it is known that the microstructure of the steel has a significant influence on the mechanical properties, and this is dependent on the heat treatment applied. This work aims to find a great time for obtaining a bainitic ferrite structure. It was observed that the bainitic transformation at $280 \mathrm{oC}$ is more effective for times greater than 300 s and that with 1.800 s treatment virtually the entire array became bainitic.
\end{abstract}

Keywords: Heat treatments, AISI 4350 steel, Bainitic microstructure.

'Faculdade de Engenharia de Guaratinguetá - Guaratinguetá (SP) - Brasil. ${ }^{2}$ Instituto de Estudos Avançados - São José dos Campos( SP) - Brasil.

Endereço para correspondência: Rosiane Castro Nogueira - UNESP - Faculdade de Engenharia de Guaratinguetá - Av. Ariberto Pereira da Cunha, n. 333, Portal das Colinas - CEP: 12516-410 - Guaratinguetá (SP) - Brasil 


\section{INTRODUÇÃO}

O microconstituinte bainítico, descoberto a menos de um século, por volta da década de 1920, tem recebido especial atenção, pois algumas investigações científicas recentes mostram que a estrutura bainítica, pode ajudar a melhorar o desempenho de novos aços.

Há uma crescente demanda pela produção de uma ampla variedade de aços bainíticos comerciais, incluindo-se entre estes os de média até ultra-alta resistência, os resistentes à fluência, os obtidos por resfriamento rápido e os com ferrita acicular inoculada. Estes aços têm sido projetados para atender a um amplo espectro de aplicações, principalmente para fins estruturais ${ }^{(3,4)}$.

Os aços temperados e revenidos foram, por algum tempo, preferidos devido aos valores de resistência ser superiores, se comparados aos aços bainíticos, porém a tecnologia moderna permite a formação de microestruturas bainíticas com elevados valores de resistência.

Geralmente, a microestrutura bainítica requer para sua melhor caracterização microestrutural a utilização da microscopia eletrônica por varredura, visto que esta estrutura é muito complexa e bastante refinada, podendo ainda apresentar diferentes morfologias (por exemplo, em forma de ripas, em forma de plaquetas, nodular, colunar, etc.).

Atualmente, sabe-se que dentre as causas apontadas como responsáveis por impedir os aços bainíticos de apresentar uma alta resistência estão à presença de carbonetos grosseiros, como a cementita, e de blocos de austenita em sua microestrutura. A cementita, que é uma fase frágil, neste constituinte pode iniciar uma trinca quando submetida à influência das tensões, e esta pode então se propagar para dentro da ferrita-bainítica sob condições apropriadas de tensão e temperatura ${ }^{(5)}$. Assim, uma possibilidade de amenizar, senão resolver completamente este problema ocorre pela adição de elementos de liga como silício, o qual na quantidade de 1,5\%, em peso, de acordo com alguns trabalhos, pode suprimir a precipitação de cementita a partir da austenita, durante a formação da bainita, desde que a força de arraste para a precipitação seja reduzida quando a cementita absorve parte do silício presente na fase original ${ }^{(6)}$.

Em aços com altos teores de silício (acima de 1\%), a microestrutura bainítica é constituída de finas placas de ferrita bainítica separadas por regiões de austenita enriquecida com carbono, sendo também possível encontrar a presença parcial de martensita ${ }^{(7,8)}$. Estes aços recebem a denominação de aços bainíticos livres de carbonetos, e a sua microestrutura, bainítica composta, tem demonstrado ser capaz de atingir a melhor combinação entre resistência e tenacidade, dentre os aços bainíticos que foram desenvolvidos até a atual data e, portanto, apresentando um limite de resistência a tração que varia de $1600 \mathrm{MPa}$ até $1800 \mathrm{MPa}$, mantendo um alongamento total maior do que $10 \%{ }^{(5,9)}$.

No entanto, uma etapa importante para o desenvolvimento destas microestruturas específicas envolve os tratamentos térmicos aos quais os aços são submetidos. Assim sendo, é indiscutível a relevante contribuição que os tratamentos térmicos escolhidos e aplicados podem oferecer, quando o interesse está na determinação de percentuais adequados de bainita ou das demais fases, que podem estar presentes: ferrita, austenita retida e/ou martensita.

Este trabalho tem por finalidade analisar a influência do tempo de permanência do aço 4350 , na temperatura de $280^{\circ} \mathrm{C}$, para a formação da estrutura bainítica. Os diferentes intervalos de tempo utilizados exercem influência sobre a fração volumétrica de bainita que será formada no aço. Esta alteração microestrutural terá reflexos nas propriedades mecânicas.

\section{MATERIAIS E MÉTODOS}

A Tabela 1 apresenta a composição química para o aço AISI 4350, produzido pela GERDAU (antiga Villares Metals S.A.) e fornecido para esta pesquisa.

Tabela 1: Composição química (\% massa) para o aço AISI 4350.

\begin{tabular}{c|c|c|c|c|c|c|c|} 
C & Mn & Si & Cr & Mo & Ni & P & S \\
\hline 0,501 & 0,70 & 0,20 & 0,80 & 0,24 & 1,71 & 0,008 & 0,012 \\
\hline
\end{tabular}

De acordo com a norma ASTM E8(10), foram confeccionados os corpos de prova (CDP's) do aço AISI 4350 para ensaios de tração. A Fig. 1 mostra o desenho esquemático dos corpos de prova.

Três lotes de corpos de prova (CDP's) foram submetidos a três diferentes rotas de tratamentos térmicos, sendo:

- Rota A: o primeiro conjunto de CDP's foi aquecido na temperatura de austenitização a $850^{\circ} \mathrm{C}$ por 900 s em forno tipo mufla, e em seguida transferido para o forno em

B

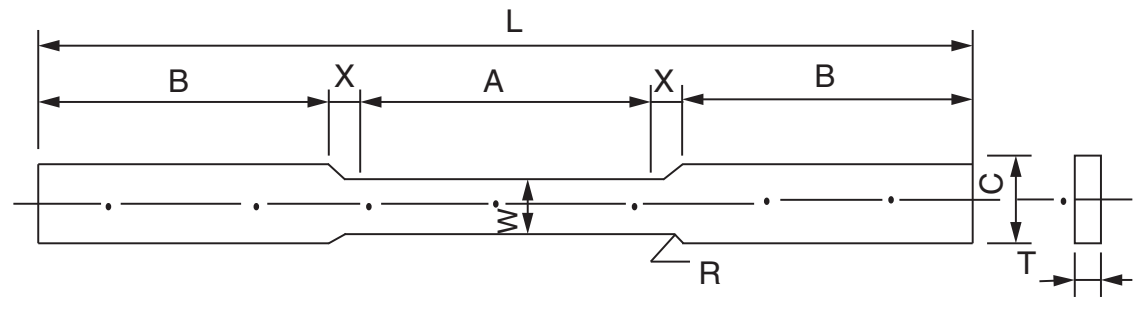

Onde:

$A=31,8 \mathrm{~mm}, \mathrm{~L}=101,6 \mathrm{~mm}$,

$\mathrm{W}=6,9 \mathrm{~mm}, \mathrm{~B}=31,8 \mathrm{~mm}$,

$\mathrm{R}=6,4 \mathrm{~mm}, \mathrm{X}=4 \mathrm{~mm}$,

$\mathrm{C}=9,5 \mathrm{~mm}, \mathrm{~T}=3,2 \mathrm{~mm}$.

Figura 1: Representação esquemática de um corpo de prova para ensaio de tração. 
banho de sal, que se encontrava na temperatura de transformação bainítica de $280^{\circ} \mathrm{C}$, onde permaneceu por 300 s.

- Rota B: o segundo conjunto de CDP's foi também aquecido em $850^{\circ} \mathrm{C}$ por 900 s em forno tipo mufla, e logo após transferido para o forno em banho de sal, que se encontrava na temperatura de transformação bainítica de $280^{\circ} \mathrm{C}$, onde permaneceu por 1800 s.

- Rota C: o terceiro conjunto de CDP's foi também aquecido em $850^{\circ} \mathrm{C}$ por 900 s em forno tipo mufla, e depois foi transferido para o forno em banho de sal, na temperatura $280^{\circ} \mathrm{C}$, onde permaneceu por 5400 s.

Em todo caso, para encerrar os tratamentos térmicos os três conjuntos de CDP's foram submetidos a um resfriamento final em água.

O esquema da Fig. 2 ilustra os tratamentos realizado

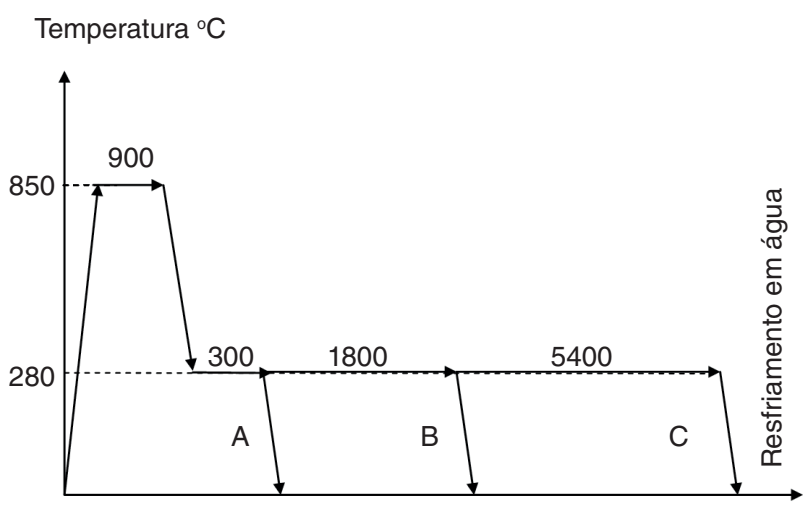

Tempo (s)

Figura 2: Esquema das rotas de tratamentos térmicos realizadas no aço AISI 4350.

Posteriormente, foi realizada a caracterização microestrutural. As amostras foram preparadas seguindo os procedimentos metalográficos: corte, embutimento, lixamento (granulometria 220 a 1500 mesh) e polimento com suspensão de sílica coloidal (OP-U).

$\mathrm{Na}$ seqüência aplicou-se a técnica de tríplice ataque, por meio da qual foram utilizados os seguintes reagentes:

- Nital 2\% (2 mL de $\mathrm{HNO}_{3}$ e $98 \mathrm{~mL}$ de álcool etílico PA), onde as microestruturas contendo ferrita e austenita retida, fases claras, se destacam das demais fases que aparecem escuras;

- Solução aquosa de metabissulfito de sódio 10\% (10\% de $\mathrm{Na}_{2} \mathrm{~S}_{2} \mathrm{O}_{5}$ diluído em água destilada), em que a austenita retida aparece com a cor mais clara, contrastando com as demais fases escuras; $\mathrm{e}$

- Reagente LePera, que é uma mistura de duas soluções, em partes iguais: uma solução aquosa de metabissulfito de sódio $1 \%$ com uma solução de ácido pícrico 4\% diluído em etanol. Com este reagente a fase clara destacará o constituinte M.A. (martensita e austenita retida) das outras fases que permanecem escuras ${ }^{(1,2)}$.

O critério utilizado para a escolha do tempo em que as superfícies das amostras deveriam permanecer expostas aos reagentes químicos para revelar as microestruturas, ou seja, o tempo de ataque, foi determinado por observação visual: quando as superfícies atacadas revelavam um aspecto embaçado (ou fosco) o ataque era interrompido, pois a perda do brilho inicial do metal mostrava que a ação do reagente já havia produzido a reação desejada. Assim sendo, para estes reagentes químicos averiguou-se um tempo de ataque entre 8 s a 10 s.

As imagens foram obtidas, com o uso do microscópio óptico, e de acordo com a norma ASTM E-1382 ${ }^{(11)}$, procedeu-se a quantificação das fases presentes. Na captura e análises destas imagens foram utilizadas os softwares AxioVision Rel. 4.8 e Image J, a partir de 20 imagens de cada tipo de ataque químico, com um aumento padrão de 200 vezes, foi possível determinar a fração volumétrica das fases presentes formadas como ferrita, bainita, martensita, além da austenita retida.

\section{RESULTADOS E DISCUSSÕES}

Com o aquecimento até a temperatura de $850^{\circ} \mathrm{C}$, a qual corresponde à região de austenitização completa, todos microconstituintes que se encontravam presentes, no aço a temperatura ambiente, são transformados em austenita ${ }^{(12)}$.

Após um rápido resfriamento até a temperatura de $280^{\circ} \mathrm{C}$, temperatura isotérmica para a transformação bainítica, na qual as amostras permaneceram imersas no banho de sal, a austenita progressivamente se transformou em bainita e o carbono excedente enriqueceu a austenita residual.

Entretanto, no resfriamento final em água, parte da austenita presente também se transformou em martensita, ao ser resfriada até a temperatura ambiente.

Com o aumento progressivo no tempo de permanência na temperatura do banho de sal $\left(280^{\circ} \mathrm{C}\right)$, há uma redução na fração volumétrica de austenita, que progressivamente se transforma em bainita e há uma pequena fração de austenita retida que se estabiliza na estrutura. Desta forma, reduz a formação de martensita que se formaria durante o resfriamento final em água, pois há uma redução na austenita disponível para esta transformação.

$\mathrm{Na}$ Fig. 3 são mostradas as imagens obtidas por microscopia óptica após realização do ataque químico com reagente nital 2\%, para as amostras submetidas às rotas de tratamentos térmicos $\mathrm{A}$, B e C, já descritas.

Nas imagens da Fig. 3, as áreas claras, correspondem aos constituintes ferrita e a austenita retida. A região escura corresponde ao percentual de bainita e martensita presente, porém se espera um maior percentual de bainita, principalmente para os tempos de permanência mais longos, como será notado após os outros ataques. 

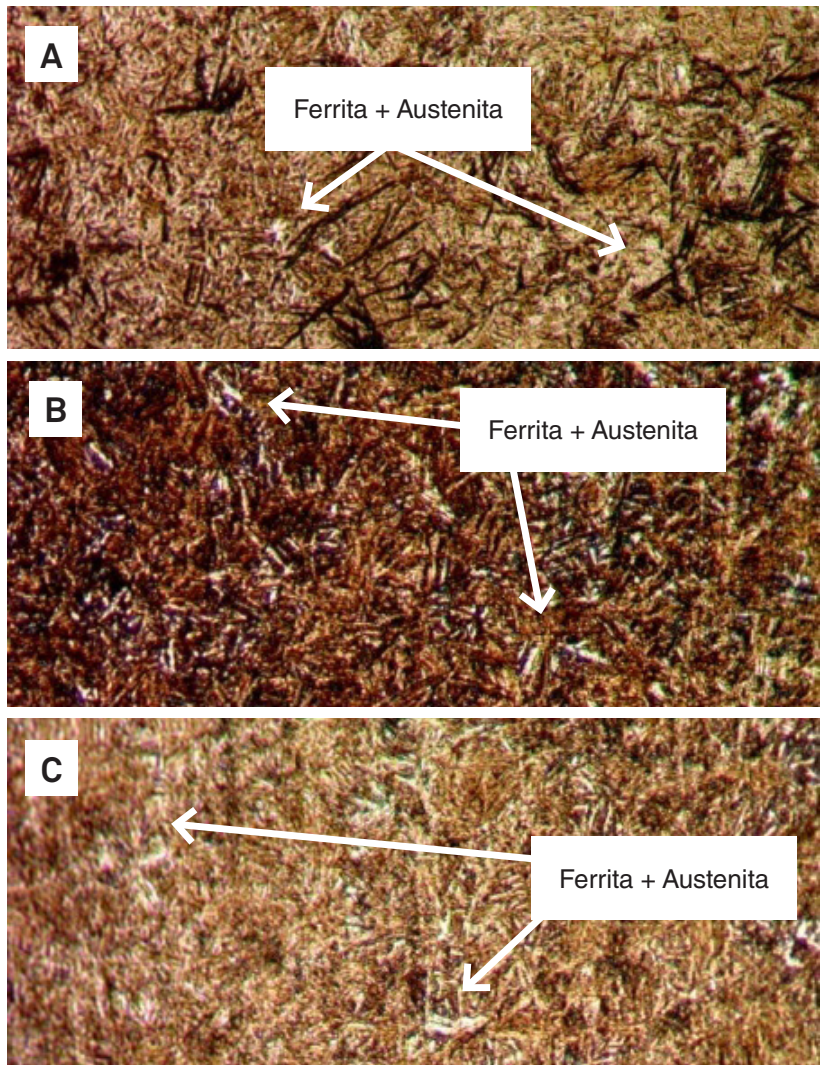

Figura 3: Imagens de microscopia óptica para as amostras do aço AISI 4350, submetidas ao ataque químico com reagente nital $2 \%$ : (A) por 300s; (B) por 1800s; (C) por $5400 \mathrm{~s}$ (escala $25 \mu \mathrm{m}$ ).

Por causa do suficiente enriquecimento de carbono ocorrido na austenita, parte desta se estabiliza na temperatura isotérmica de $280^{\circ} \mathrm{C}$, não sofrendo posteriormente transformação em martensita durante o resfriamento final em água ${ }^{(3)}$.

A Fig. 4 mostra imagens obtidas por microscopia óptica, após o ataque com o reagente metabissulfito de sódio $10 \%$. Por este ataque a austenita retida é destacada dos demais constituinte por apresentar-se com a cor clara.

Nota-se pelas imagens da Fig. 4 que apenas a austenita apresenta-se com a cor branca, as outras fases aparecem com cores mais escuras $^{(1)}$. Por este ataque químico se extrai a fração volumétrica de austenita retida. As imagens foram convertidas em escala de cinzas para destacar a fase de cor branca.

A Fig. 5, monstra as imagens por microscopia óptica após o ataque com reativo LePera, para amostras submetidas aos tratamentos térmicos $\mathrm{A}, \mathrm{B}$ e $\mathrm{C}$.

Ao observar a Fig. 5, em todas as imagens, percebe-se a existência de algumas áreas claras, que indicam a presença do constituinte M.A. (martensita + austenita retida). As áreas em tom de marrom mais escura, que correspondem à maior parte das imagens da Figs. 5B e 5C, indicam a presença da fase bainítica. A tonalidade mais para o bege na Fig. 5A mostra a presença predominante de martensita, indicando que no tempo de 300s houve pouca transformação de autenita em bainita e a maior parte de austenita na estrutura se transformou em martensita durante o resfriamento final.
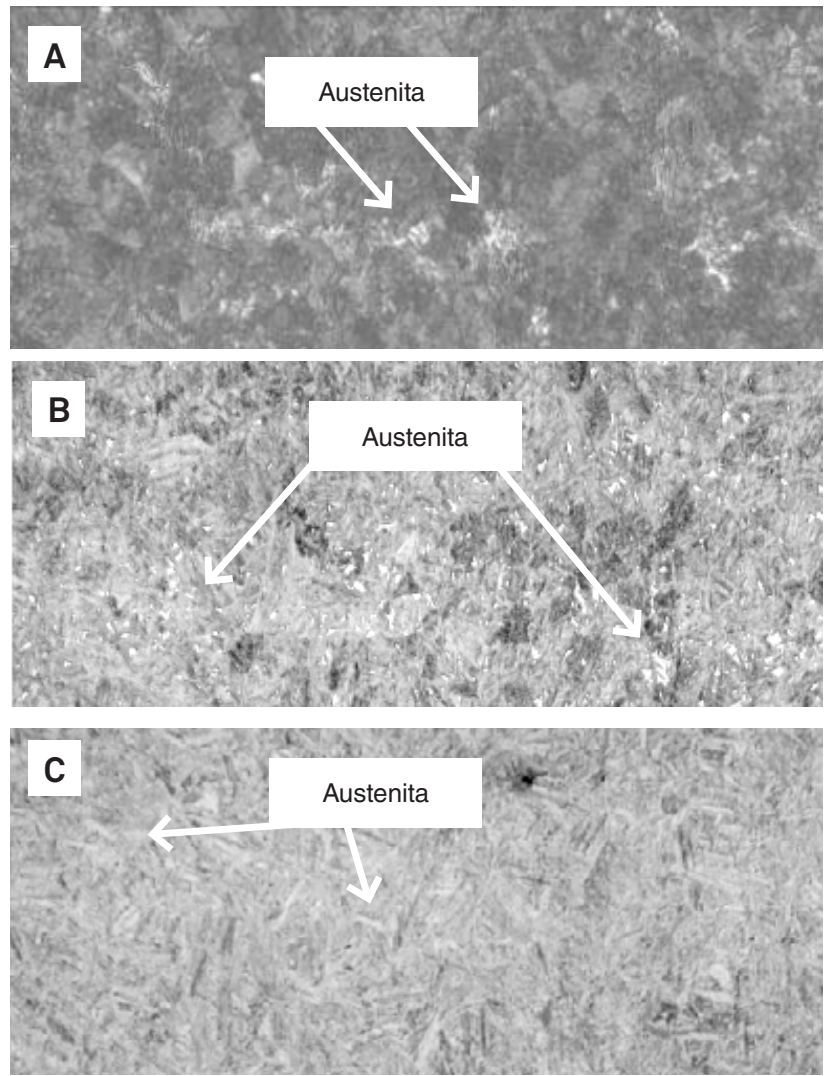

Figura 4: Imagens por microscopia óptica de amostras do aço AISI 4350 após ataque químico com solução aquosa de metabissulfito de sódio 10\%: (A) por 300s, (B) por 1800s e (C) por 5400 s (escala $20 \mu \mathrm{m}$ ).
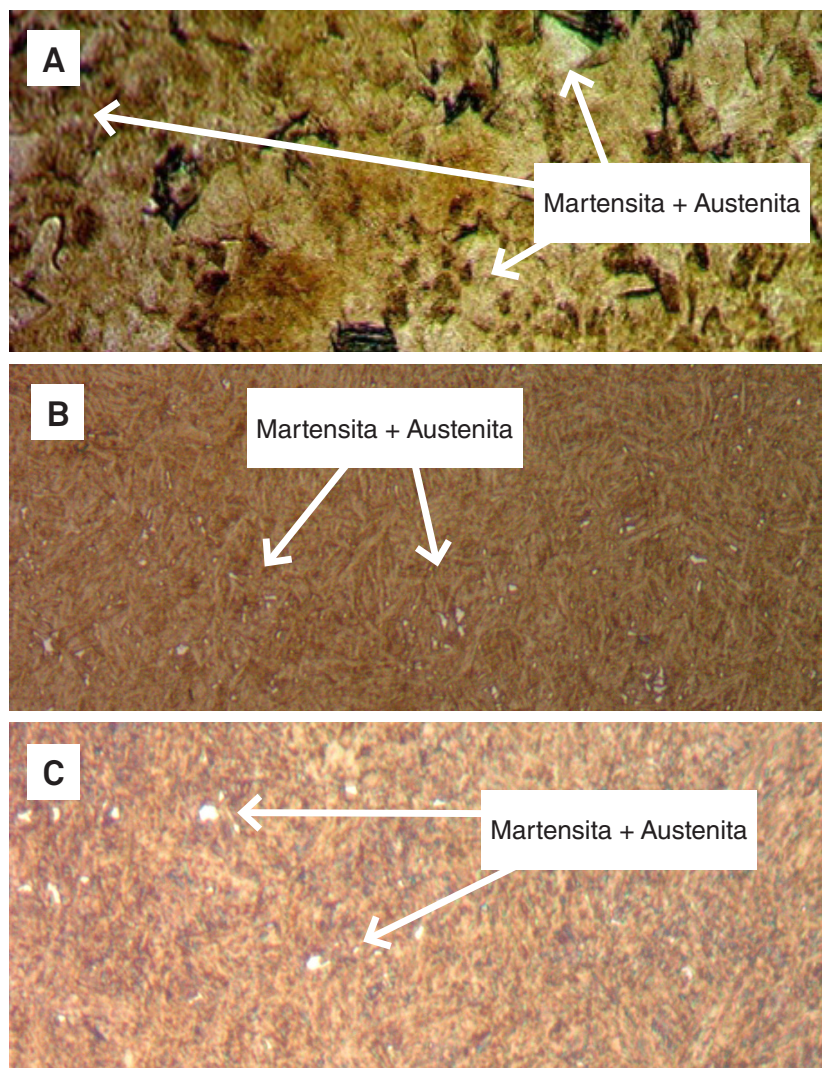

Figura 5: Imagens por microscopia óptica de amostras do aço AISI 4350 após ataque químico com o reativo LePera: (A) por $300 \mathrm{~s}$; (B) por $1800 \mathrm{~s}$; (C) por $5400 \mathrm{~s}$ (escala $25 \mu \mathrm{m})$. 
Com a aplicação da técnica de tríplice ataque químico e com o uso do microscópio óptico foram feitas as análises estatísticas a partir de 20 imagens de cada tipo de ataque, para cada condição de tratamento estudada. Foi então determinada a fração volumétrica das fases formadas como ferrita, bainita, martensita, além da austenita retida ${ }^{(2)}$.

$\mathrm{Na}$ Tabela 2, são apresentadas as frações volumétricas das fases produzidas, para os três conjuntos de corpos-de-prova (CDP's) do aço AISI 4350, após aquecimento até a temperatura de austenitização de $850^{\circ} \mathrm{C}$ por 900 s, com subseqüente resfriamento e manutenção na temperatura isotérmica de transformação bainítica de $280^{\circ} \mathrm{C}$ por 300s (Rota A), 1800 s (Rota B) e 5400s (Rota C).

Ao observar a Tabela 2, percebeu-se uma pequena quantidade de ferrita formada, à qual quando em quantidade significativa pode propiciar uma melhoria na ductilidade do material, porém, em contraposição, há uma redução nos valores de dureza e resistência mecânica. Isto ocorreu porque durante os tratamentos térmicos após o aquecimento dos CDP's na temperatura de $850^{\circ} \mathrm{C}$, correspondente à região de austenitização completa, houve transferência destes CDP's para outro forno em banho de sal na temperatura de $280^{\circ} \mathrm{C}$, temperatura correspondente à faixa de transformação bainítica, com o propósito de propiciar um rápido resfriamento dos mesmos, o que inibiu a formação de ferrita e perlita nestas estruturas.

Pela análise da Tabela 2 constatou-se também através dos valores encontrados, que o resfriamento até a temperatura de transformação bainítica de $280^{\circ} \mathrm{C}$ e, permanência nesta por diferentes intervalos de tempo, permitiu a obtenção de uma estrutura final com o predomínio de bainita, para os tempos de permanência de 1.800 s e de 5.400 s. Para o tempo mais curto de permanência houve uma formação de bainita reduzida $(8,7 \%)$ com uma estrutura predominante martensítica que, por ser frágil, necessitaria passar por um tratamento de revenido para melhorar a tenacidade.

Para as estruturas que se formaram nos tempos de 1800 s e de 5400s, percebeu-se que as frações volumétricas das fases presentes não apresentaram alterações significativas com o aumento do tempo de transformação bainítica.

\section{CONCLUSÕES}

A partir da análise das informações apresentadas na Tabela 2, é possível deduzir, para o aço estudado, que a transformação bainítica na temperatura de $280^{\circ} \mathrm{C}$ foi mais efetiva para os tempos mais prolongados (1.800 e 5.400s). Para o tempo de 300s ocorreu a transformação de pequena parcela da austenita $(8,7 \%) \mathrm{em}$ bainita, e assim, grande parte desta austenita transformou-se em martensita durante o resfriamento final em água. Para o tempo de 1.800 s de permanência a $280^{\circ} \mathrm{C}$ praticamente toda a matriz do aço já havia se tornado bainítica.

Os tratamentos térmicos aplicados, também permitiram a formação de pequenas quantidades de ferrita e austenita retida, e embora estes percentuais somados fiquem em torno de $10 \%$, estas fases podem contribuir para aumentar a ductilidade do material.

\section{AGRADECIMENTOS}

Os autores agradecem a CAPES pela bolsa de doutorado e demais recursos, referente ao projeto Pró-Defesa 014/2008, e a Faculdade de Engenharia de Guaratinguetá - UNESP.

Tabela 2: Frações volumétricas das fases ferrita, austenita retida, bainita e martensita, com os respectivos desvios padrão.

\begin{tabular}{|c|c|c|c|c|}
\hline Rotas/Tempo (s) & \% Ferrita & \% Austenita retida & $\%$ Bainita & $\%$ Martensita \\
\hline A - $300 \mathrm{~s}$ & $1,8 \pm 0,9$ & $8,6 \pm 0,9$ & $8,7 \pm 0,9$ & $80,9 \pm 0,9$ \\
\hline B - $1800 \mathrm{~s}$ & $1,4 \pm 0,2$ & $8,7 \pm 0,2$ & $81,6 \pm 0,2$ & $7,9 \pm 0,2$ \\
\hline C - $5400 \mathrm{~s}$ & $1,4 \pm 0,2$ & $9,0 \pm 1,9$ & $82,7 \pm 1,9$ & $6,9 \pm 1,9$ \\
\hline
\end{tabular}

\section{REFERÊNCIAS}

1. ANAZAWA, R.M.; ABDALLA, A.J.; HASHIMOTO, T.M.; PEREIRA, M.S. Revista Brasileira de Aplicações de Vácuo 25 (2006) 93

2. HASHIMOTO, T.M.; SILVA, A.P.; PEREIRA, M.S.; ABDALLA, A.J. Anais do 17o Congresso Brasileiro de Engenharia e Ciência dos Materiais, Foz do Iguaçu, Brasil, 2006, p.5610

3. YOOZBASHI, M.N.; YAZDANI, S.; WANG, T.S. Materials and Design 32 (2011) 3248.

4. LUO, Y.; PENG, J.; WANG, H.; WU, X. Materials Science and Engineering A 527 (2010) 3433.

5. CABALLERO, F.G.; CHAO, J.; CORNIDE, J.; GARCÍA-MATEO, C.: SANTOFIMIA, M.J.; CAPDEVILA, C. Materials Science and Engineering A 525 (2009) 87.

6. KOZESCHNIK, E.; BHADESHIA, H.K.D.H. Materials Science Technology 24 (2008) 343
7. CABALLERO, F.G.: SANTOFIMIA, M.J.: GARCÍA-MATEO, C.: CHAO, J.; GARCÍA DE ANDRÉS, C. Materials and Design 30 (2009) 2077.

8. CABALLERO, F.G.; MILLER, M.K.; CLARKE, A.J.; GARCÍAMATEO, C. Scripta Materialia 63 (2010) 442

9. CHANG, L.C. Wear 258 (2005) 730.

10. ASTM E8/E8M -13a - Standard Test Methods for Tension Testing of Metallic Materials. USA: ASTM International; 2013.

11. ASTM E1382-97. Standard Test Methods for Determining Average Grain Size Using Semiautomatic and Automatic Image Analysis. USA: ASTM International; 2010.

12. SILVA, A.P., Estudo da transformação da austenita retida induzida por deformação, em um aço AISI 4340 com estrutura multifásica. Tese de Doutorado (2006). Faculdade de Engenharia de Guaratinguetá, Universidade Estadual Paulista, Guaratinguetá (SP). 